Notas

\author{
JERZY KÜHN
}

\title{
Las metamorfosis de Cortázar
}

En el enredo de veredas por las cuales avanza la historia de la literatura argentina actual se puede trazar —entre otras - una línea distinguible, que correría de Macedonio Fernández a Borges y se dividiría luego en tres - Bioy Casares, Sabato, Cortázar- para llegar a otras divisiones ya menos importantes. Es una operación casi indispensable, porque hasta hoy se suele mirar a los escritores del boom como a fenómenos autógenos, como a isletas de un océano sin literatura del que habrían emergido de golpe, como por efecto de un milagro. Además de examinar esta línea y otras semejantes me referiré no sólo a entrelazamientos y dependencias que juntan la creación de escritores de varias generaciones, sino también a los cambios de conciencia en sus destinarios - lectores y críticos.

Cuando a fines de los años treinta, Jorge Luis Borges publicó en las columnas de la revista Sur sus primeros cuentos (que iban a aparecer, en 1942 en El jardín de los senderos que se bifurcan) encontró una acogida poco benévola. A los lectores los desorientaban intrincados sofismas, sorprendentes meandros del pensamiento basados en paradojas, soluciones absurdas. Se indignaban, lo mismo que la mayoría de los críticos, por el cosmopolitismo de esos cuentos, cuya trama se desarrollaba en países extranjeros o ficticios y cuyos protagonistas tenían nombres de forasteros.

$\mathrm{Al}$ referirse a las literaturas y filosofias de Oriente y de Europa, al poner lado a lado a Berkeley, Hume y Schopenhauer con Plotino y los taoístas, con la cábala y la teología del Islam y al otorgar a esta síntesis el rango de valor principal, el autor de Ficciones asumió el papel de un sacerdote de la cultura universal, de la única, a fin de cuentas, religión, a la cual le gustaba servir. Mientras tanto los lectores y los críticos argentinos lo quisieron ver vestido con un traje litúrgico de colores nacionales. Este era -opinaban - su deber, por ser uno de los más importantes personajes en la vida artística y cultural del país. Por eso recibieron con disgusto los jardines chinos y los templos hindúes, y casi le reprocharon a su creador haber traicionado a la patria. No les irritaba menos lo excéntrico de esta narrativa fantástica. Aunque acostumbrados a la literatura fantástica - sus orígenes en Argentina se remontan a mediados del siglo XIX y el mismo Borges reconoció predecesores eminentes - los argentinos consideraban que este género era secundario, digno sólo de llenar un margen en la creación de un escritor "ver- 
dadero". Les irritaba, en fin, y los confundía la ironía y el humor absurdo que saturaban las páginas de la narrativa borgiana. El lector no estaba seguro de que el autor no se burlara de él. Hasta ese momonto, pues, la literatura argentina, incluso la fantástica, había sido funeralmente solemne. El humor, sí, pudo existir, pero en la sátira. La literatura llamada ambiciosa debía presentarse con un corsé de seriedad y sus lectores se sentaban a leerla con un recogimiento esnob. De modo que los cuentos del volumen mencionado, así como los de Ficciones, publicados años más tarde, constituían un reto a sus gustos. No es pues de extrañar el hecho de que, a pesar de su posición en la literatura argentina, el autor de La muerte y la brújula fue hasta el fin de los años cuarenta un escritor más destacado que admirado. Pero el interés hacia sus cuentos en Francia y la atención que le prestó Roger Caillois influyeron en un cambio de opinión en sus lectores y críticos de Argentina.

Diez años después de Borges, Cortázar repitió en otra forma sus propuestas. Bestiario apareció en 1941, Final del juego y Las armas secretas en 1956. El autor de esos cuentos tenía ya los senderos despejados. Los años cincuenta en la literatura argentina fueron los del triunfo de Borges, que gozaba de un reconocimiento internacional cada vez mayor. Así pues, aunque las primeras colecciones de cuentos de Julio Cortázar, residente desde 1951 en París, no encontraron de inmediato una recepción calurosa, no inspiraron por lo menos tantas objeciones como la narrativa del autor de El aleph. El mundo del absurdo ya era vigente, el teatro del sueño, la visión kafkiana no eran ya ajenos, sino como un pronóstico de lo que veintitantos años después iba a ser una realidad.

Hay que admitir que el autor de La autopista del Sur se daba cuenta de la deuda con Borges y conservaba su gratitud hacia el maestro. Hablaba de él con una lealtad extraordinaria (v. gr. en La vuelta al día en ochenta mundos) al mismo tiempo que representantes de la izquierda, con la cual Cortázar estaba ligado, atacaban desmesuradamente al escritor ciego por sus declaraciones políticas. Por lo demás, el mismo Cortázar no se sentía libre de ataques. Los puristas lingüísticos que lo anatemizaban por haber emigrado, le señalaban sus arcaísmos en el lenguaje común. Clamaban fuertemente que la jerga que él usaba a menudo no se hablaba en Argentina desde hacía veinte años, por lo que algunos de sus diálogos resultaban incomprensibles y que con el tiempo pasado fuera del país el autor de Rayuela se había convertido en un extranjero para la literatura nacional. Claro que la separación del idioma vivo y lo cotidiano de la patria no deja de tener su influencia en la obra del escritor. Sin embargo, treinta años de su vida en Argentina bastaron para que Cortázar fuera un escritor argentino que escribía sobre todo para los argentinos. Pero frente a los ataques de los "patriotas" que, con un afán digno de mejor causa, buscaban en sus libros palabras y giros fuera de circulación o le reprochaban su ciudadanía francesa, el escritor simplemente callaba. Más seriamente, en cambio, y para su desgracia, hacía frente a otro reproche, con el que le salían intelectuales de izquierda: la indiferencia del narrador ante los problemas de la literatura "com- 
prometida". Así, aunque seguía sosteniendo que no. se debían mezclar manifiestos políticos con literatura, sus publicaciones de la segunda mitad de los setenta - El libro de Manuel o Último round - indicaban que el escritor había empezado a rectificar su actitud creativa. "Hoy entiendo que la literatura que es un producto de la imaginación pura no basta (...) En la realidad de hoy el camino de la especulación puramente mental lo puede desviar a uno, como en el caso de Borges", dijo en una conversación con Zofia Chadzynska, su traductora al polaco.

Y así como Sabato, heredero de Borges en la disciplinada construcción de El túnel, negaría el mundo de la idea e imagen ordenada en Abaddón el exterminador, lo mismo Cortázar parecía dirigirse hacia una negación semejante. Esto se veía ya desde sus primeros tomos de cuentos. El autor de Rayuela tomó de Borges su predilección por las filosofias de Oriente, su universalismo cultural y su desconfianza hacia un realismo estrechamente concebido. "Casi todos mis cuentos-dijo en una conferencia dictada en la Habana en 1962- pertenecen al género que por falta de un término mejor se le suele llamar fantástico y se oponen a ese falso realismo que consiste en la fe de que todo se puede describir y explicar, como lo proclamaba el optimismo filosófico y científico del siglo XVIII, es decir dentro de un mundo regido más o menos armoniosamente por un sistema de leyes, reglas, relaciones de causas y resultados, de psicologías definidas y de geografías bien documentadas."

Esta frase la podría decir, con otro estilo, Borges. Pero la narrativa de Borges y la de Cortázar son, a pesar de sus parentescos, totalmente diferentes. Borges se parece más a la pintura de Giorgio de Chirico con sus maniquíes de cabezas ovaladas desprovistas de caras, y Cortázar a Paul Delvaux, donde en un escenario tan irreal y soñoliento como el del primero vagan personas inverosímiles, pero, de todos modos, humanas. Un poco como los paisajes poéticos de Magritte, como ése de la nube que pasa por una entreabierta puerta solitaria en la playa, o aquél con fragmentos de un paisaje rememorados en pedazos de un vidrio roto de la ventana. El mundo de Borges es absolutamente intelectual, matemático, perfecto. Borges es un jeroglífico, una geometría pura, una lógica de computadora. Es una idea cristalizada moviéndose con precisión en los laberintos del tiempo y del espacio. Cortázar había heredado este mundo desde su infancia y, como dijo, le fascinaban los laberintos y lo entusiasmaba lo fantástico, que transformó en algo suyo. Pero, a una demencia fría añadió la flama de la locura, a la lógica estricta juntó el elemento de una poesía inquietante e hizo otro uso del humor, que en Borges aparece con una moderación inglesa. Hizo del humor -como el autor de Ficciones lo hizo de su universalismo cultural- el valor primero en su literatura, un instrumento de autopsicoterapia, hasta de socio-psicoterapia. Por lo demás - hay que añadirlo al confrontar la creación de ambos escritores-, fuera del recreado tejido borgiano en la narrativa de Cortázar y fuera del Kafka que les une en el clima de algunos cuentos, ambos revelan otras influencias y parentescos. Los nexos de Borges hay que buscarlos antes que 
nada en las letras anglosajonas, los de Cortázar en las francesas. Michaux, Ponge, Jarry y los pintores surrealistas, tan próximos a él en su atmósfera, se juntaron para crear este modelo del cual derivan los cuentos y las novelas de Cortázar.

Al escribir hace tiempo sobre los cuentos de Cortázar acudí a la definición que él mismo hace del jazz, cuando habla del take —varias repeticiones del mismo motivo: Diferencia entre "ensayo" y take. El ensayo va llevando prácticamente a la perfección, no cuenta como producto, es presente en función de futuro. En el take la creación incluye su propia crítica y por eso no se interrumpe muchas veces para recomenzar; la insuficiencia o el fracaso de un take vale como un ensayo para el siguiente, pero el siguiente no es nunca el anterior en mejor, sino es siempre otra cosa si realmente es bueno. (La vuelta al día en ochenta mundos.)

Una comparación así viene dada por ella misma si leemos los libros de cuentos de Cortázar según los años de su publicación, ya que recogidos en un tomo completo y desprovistos de fechas es más difícil observar regresos a los mismos climas y motivos. Pero basta disponerlos en un orden cronológico para avanzar el diagnóstico: Cortázar escribe takes. Siempre está rondando las mismas regiones, estudia las mismas zonas de la existencia humana, regresa constantemente a los mismos laberintos, estructuras cerradas donde en una atmósfera pegajosa de sueño, de inquietud, de horror y de enemistad gratuita, sus protagonistas se mueven sin voluntad, o más bien contra su voluntad. Construye sus sorpresas, verifica innumerables variantes del juego, cuyo esquema es en la mayoría de los casos el mismo: la irrupción de lo absurdo en una realidad cotidiana. Porque aunque escriba un cuento realista, es lo fantástico, lo absurdo, un espejo más o menos curvado de la realidad lo que predomina en su narrativa. $\mathrm{Y}$ además el realismo cortazariano parece en general un realismo muy dudoso. Casi siempre contiene algún elemento de lo no cotidiano, de lo diferente; está saturado de un clima de inquietud y hasta de horror, que sugiere sospechas de algún ocultamiento de otra cosa.

Si no están ellos mismos marcados por un estigma de lo distinto, de lo irreal, los protagonistas de los cuentos cortazarianos tropiezan con ello en algún momento y, por lo general contra su propia voluntad, participan en acontecimientos cuyo sentido se escapa a su razonamiento y se opone a todo sentido de sano juicio. Pero, lo mismo que en el sueño, sus esfuerzos para salir de la situación y regresar a la normalidad no sirven para nada. Los protagonistas se hallan arrojados dentro de un juego que los obliga a aceptar sus reglas, dentro un juego en el que la apuesta es su destino.

El mundo absurdo, la realidad absurda no sólo surgen de la anécdota de la narrativa cortazariana, sino aparecen explícitamente. La palabra "absurdo" se encuentra muchas veces en las páginas de Los premios, se discute su definición en Rayuela. Y no se trata allí tanto de un absurdo ontológico, del absurdo camusiano de la existencia, como del absurdo epistemológico, de nuestra percepción de la realidad. El mundo — nos 
da a entender Cortázar - no es absurdo en sí mismo, sino que es así porque, nos permitimos ser dominados por la rutina de los ademanes cotidianos y los hábitos mentales. Consumimos la realidad, aceptamos todo sin la menor sorpresa, ni siquiera nos esforzamos en estudiar la esencia de los fenómenos ocultos bajo la superficie. "El absurdo es (dice Oliveira) que salgas por la mañana a la puerta y encuentres la botella de leche en el umbral y te quedes tan tranquilo porque ayer te pasó lo mismo y mañana te volverá a pasar. Es ese estancamiento, ese así sea, esa sospechosa carencia de excepciones."

Cortázar el cuentista, no trataba de convertir a nadie. Sospecho que él mismo no estaba seguro de cómo era o si existía otra cara de nuestra realidad. Quiso solamente despertar a sus lectores de su letargo, inocularles la inquietud. No queremos cambiar nada en las costumbres de la gente - proclamaba una declaración de la Oficina de Búsquedas Surrealistas (1925) - pero queremos demostrarles la fragilidad de sus ideas y en qué inciertos fundamentos, encima de qué calabozos construyeron sus casas tambaleantes. El autor de Las armas secretas podría firmar este manifiesto.

Los que me reprochan escribir novelas, donde casi continuamente se pone en duda lo que acuba de afirmarse o se a firma empecinadamente toda razón de duda insisten en que lo más aceptable de mi literatura son algunos cuentos, donde se advierte una creación unívoca, sin miradas hacia atrás o paseitos hamletianos dentro de la estructura misma de lo narrado. Haciendo un comentario a comentarios críticos en torno de su propia creación (en La vuelta al día en ochenta mundos) Cortázar se opone decididamente a contraponer ambos géneros. (Mis cuentos - dice más adelante-) mal o bien escritos, son en su mayoría de la misma estofa que mis novelas (...) Rayuela es de alguna manera la filosofía de mis cuentos, una indagación sobre lo que determinó a lo largo de muchos años su materia o su impulso. Sin embargo, fue Rayuela la que abrió a su autor, también en Polonia, las puertas de la fama. Y fueron precisamente las novelas, esa "menos digerible" parte de su obra, las que arrojaron más luz sobre la persona de Cortázar cuentista y fueron ellas también, más que los cuentos, que los collages literarios - como La vuelta al día en ochenta mundos y Último Round - más que las poesías, en su mayoría de no muy alto vuelo, las que señalaban los cambios en su obra. Los premios (1960), Rayuela (1963), 62 Modelo para armar (1969) y El libro de Manuel (1973) agotan la lista.

Los premios es como un libro de otro autor, de un lector diligente de Kafka (sobre todo el de $\mathrm{El}$ castillo) que no ha entrado todavía en el camino de los experimentos formales. En las tres siguientes se puede observar, cada vez más intensivo, el proceso de quebrantamiento de la estructura narrativa, que no alcanza en verdad, como en Vargas Llosa, el tejido de la misma frase, pero que al seguir al nouveau roman francés rompe en pedazos el flujo del fabular. En Rayuela el autor propone a su lector un laberinto de capítulos que hay que atravesar según la guía indicada en el prólogo al libro. Así, pues, hay que leer al principio el libro en su orden natural, para pasar después al segundo libro, que irrumpe en el terreno del primero. De este armazón nace un modelo nuevo en 
relación con la primera parte, multisignificativo en sus soluciones fabulares. Es mucho más un modelo para armar que la tercera novela, que tiene este título, en la cual el. lector, al recibir pedazos de la narración junto a la propuesta del autor de que los arme él mismo, recibe, en realidad, un modelo ya armado. Su orden obedece a las leyes de la composición y cada desplazamiento de esos trozos fabulados produciría el sacudimiento de esta composición. Pero no se trata, pues, de si los capítulos de Rayuela se pueden leer en otro orden, o si el modelo de composición en 62 Modelo para armar se puede ordenar de otra manera de como lo hizo el autor. (Dicho sea de paso, la novedad formal de esta novela no consiste en su estructura, sino en la explicitación de su potencialidad). La cosa es que ambos libros son en cuanto a su libertad (desenvoltura) constructiva una antípoda de la primera novela que narra su anécdota de modo tradicional, cronológicamente.

El libro de Manuel supera en su novedad formal a las novelas anteriores. Aquí, en la corriente de la narración, por lo demás más ordenada cronológicamente que en Rayuela y en 62 Modelo para armar introdujo Cortázar elementos ajenos a la narrativa tradicional, como poemas, dibujos, diagramas, injertos en bastardilla, tablas, fragmentos de cartas y, además, varios recortes de prensa cuya presencia explica el título de la novela: El libro de Manuel. (En el futuro deberán ser material de lectura de Manuel, hijo de una pareja de protagonistas.) Esa técnica del collage, un nourum en las novelas de Cortázar, tiene sus antecedentes en otras esferas de su literatura, en las heteromórficas colecciones como es La vuelta al día en ochenta mundos, un libro cuyo rasgo principal es aquella extraña mezcla de materia: unión de ensayo con folletín, poesía, cuento, fragmentos de memorias y reflexiones personales, y todo ello con abundantes ilustraciones y fotografias; un libro, comprueban sus lectores, muy desigual, que contiene unos textos excelentes, como el ensayo "Para llegar a Lezama Lima", pero también muchas banalidades. Lo mismo se puede decir de otro tomo de ese tipo (o precisamente dos tomos, editados - para que fuera más extraño- en diversos tamaños): Último round. Aquí también, en esa mezcla de materia, se pueden encontrar textos buenos - los cuentos "Siestas" y "El viaje", un ensayo sobre Dalí y otro sobre el erotismo en la literatura de lengua españolapero lo que predomina es una papilla indigerible. Parece como si Cortázar hubiera creído por entonces que cada texto que salía de su pluma era excelente; creencia muy nociva para el autor.

Pero mucho más daño le hicieron esos críticos que le exigieron un compromiso político unívoco en el campo de la literatura. Mientras el autor de 62 Modelo para armar cedió sólo en el terreno de sus misceláneas, salió victorioso de las batallas con el material narrativo, creando cada vez nuevas fascinaciones. Pero Cortázar, cansado de repetir constantemente los mismos argumentos, decidió por fin escribir una novela que reuniera los valores artísticos y la ideología. El libro de Manuel es el resultado de esta decisión.

En una entrevista para la revista peruana Textual (junio 1973), 
Cortázar repite su tantas veces expresada opinión de que no hay que confundir la literatura con un mensaje político: Todos conocen muchos fracasos, a menudo patéticos, de los esfuerzos de este tipo, donde todos salen perdidos: un lector de novelas y un buscador de manifiestos (...) No creo que sea posible hervir definidas tesis ideologicas en una salsa literaria (...) veo, en cambio, una posibilidad de convergencia, de simultaneidad, donde lo que se suele llamar la forma y el contenido, el fondo y la narración aparecerían en el mismo proceso creativo.

En la novela latinoamericana los intentos de reunir mensaje social y literatura habían fracasado siempre que el autor olvidaba que estaba escribiendo una obra literaria y no un manifiesto, pero por cierto también es verdad que puede existir una narrativa que al tocar los más acuciantes, los más actuales problemas del continente no traicione su forma artística de expresión.

Entre los compatriotas del autor de Los premios, se encuentran escritores que lo han logrado perfectamente. Ernesto Sabato en Abaddón el exterminador tiene escenas que son fuertes acusaciones a la dictadura argentina. O, por ejemplo, Haroldo Conti, quince años menor que Sabáto y Cortázar. Su novela Mascaró, el cazador americano (1975) es, sin ninguna duda, una novela política, pero es sobre todo una novela con todos los requisitos estéticos concomitantes a esta denominación. Ambos autores tenían un contacto cotidiano con la realidad descrita. Sus novelas son, pues, testimonios de una realidad que se encuentra al alcance de la mano. Tales ejemplos se pueden enconitrar más ampliamente en la literatura latinoamericana. Pero en cada caso son creaciones cuyo mensaje ideológico surge de una manera natural de la totalidad de la obra. En El libro de Manuel, nacido del otro lado del océano, en un exilio cómodo, no se ve esta espontaneidad, esta compulsión interior. Es un libro concebido de principio a fin en la atmósfera de las novelas anteriores, pero según una tesis preconcebida.

Rayuela, 62 Modelo para armar y El libro de Manuel tienen muchos rasgos comunes. Los relaciona no solamente la atmósfera, un desvanecimiento perpetuo de los límites entre la realidad y la fantasía, su predilección por lo grotesco, por lo absurdo y la novedad formal (en $E l$ libro de Manuel no siempre motivada), pero también la actitud de los principales protagonistas. Pues al imaginar sus ademanes y sus acciones, al escuchar sus diálogos, se puede fácilmente llegar a la conclusión de que en las tres novelas actúan los mismos protagonistas, a quienes el autor ha cambiado solamente sus nombres: los outsiders que se rebelan contra la estabilización del mundo, intelectuales, artistas, que forman un conglomerado internacional: franceses, latinoamericanos, españoles, anglosajones - en El libro de Manuel aparece incluso una polaca-, gente que por su estilo de vida, por su sentimiento de alienación, se aglomera en asociaciones informales: el Club de la Serpiente, en Rayuela; la Zona, en 62 Modelo para armar; la Joda, en El libro de Manuel.

En el plano ontológico, a los protagonistas de El libro de Manuel y de las dos novelas anteriores los divide un abismo que resulta de las diferen- 
tes características de estos libros. Rayuela y 62 Modelo para armar son novelas "existenciales". Sus héroes buscan, como Horacio Oliveira, el sentido de la existencia que se les escapa, o quedan anclados, como los protagonistas de 62. Mudelo para armar, en la irrealización (incumplimiento), en un vacío existencial. Habitados por una vacilación interna, por una eterna incertidumbre, rechazan decididamente el modelo de vida que les ofrece la realidad, pero no pueden contraponerle ningún valor positivo. Esa actitud de negación total, de duda absoluta frente al sentido de cualquier acción, se descarga en actitudes suplementarias, como navegar en una lancha provista de un motor de máquina para cortar hierba o transportar un paquete de mate y clavos a través de un puente construido entre dos ventanas enfrentadas; todo eso les otorga una dimensión trágica. En El libro de Manuel, en cambio, Cortázar no permite a ninguno de sus protagonistas ninguna duda. Ellos también, como los héroes de Rayuela y 62 Modelo para armar, pasan mucho tiempo en fiestas comunes, hacen el amor (más frecuentemente que en las novelas anteriores), colectan recortes de prensa, unívocos en su sentido político, disputan entre sí, pero - y eso los diferencia de los personajes de aquellas novelas - sobre todo actúan. El eje de acción, alrededor del cual se concentran otros acontecimientos, es el secuestro de un dictador latinoamericano que está en París. Se le piensa cambiar por presos políticos de varias cárceles latinoamericanas. En el preparativo de esta acción trabajan todos los protagonistas. El único escéptico de este grupo, es Andrés Fava, que al principio se queda aparte, pero se adhiere cuando le llega la noticia de que se encuentra con ellos la polaca Ludmila, quien lo ha abandonado yéndose con otro integrante del grupo. Así pues, en comparación con los protagonistas de las novelas anteriores, los de El libro de Manuel parecen ser personajes bidimensionales, simplificados. Los reviste la solemnidad de la causa política que contagia a todo el libro. No hay aquí el humor de otras novelas y cuentos. La única escena humorística, verdaderamente exquisita, es la caminata de un pingüino turquesa que después de una pelea con los gorilas del dictador abandona su canasta y se va de paseo rumbo al Sena. A las otras escenas les falta esa chispa de locura, tan bien conocida por los lectores de Cortázar. Sin embargo, si hay algo en que El libro de Manuel supera a otras novelas, es seguramente en la cantidad y calidad de sus escenas eróticas. Ya en Último Round, en el ensayo "Que sepa abrir la puerta para ir a jugar", Cortázar se lamentaba del bajo nivel artístico de las escenas eróticas en las literaturas de habla española. En El libro de Manuel logró probar que el idioma español, tan ágil como cualquier otro, puede describir escenas de la vida erótica sin caer en vulgaridad o patetismo. Porque, simplificando las cosas, los protagonistas de esta novela dividen su tiempo entre el erotismo y la conspiración. Durante su lectura siempre tuve la impresión de que en sus primeras novelas el autor escribía con más convicción.

La afirmación anterior ("Cortázar escribe takes") supone que en cada nuevo tomo de sus cuentos van a aparecer los mismos temas y motivos, 
los mismos climas, inquietudes, búsquedas. Y, en realidad, las siguientes publicaciones comprueban esta hipótesis. Asimismo su colección de cuentos Alguien que anda por ahí no difiere en ese aspecto de las anteriores. Cada uno de los cuentos que contiene podría seguramente encontrarse en tomos precedentes. Cada uno encontraría alguna "pareja", alguna afinidad que permitiría colocarlo en algún otro de sus libros. Sin embargo, recogidos en una misma colección, los cuentos de Alguien que anda por ahí dan la impresión de que es un tomo de alguna manera distinto y al mismo tiempo más homogéneo que los anteriores.

No se trata solamente de eso, pues al contrario de las otras colecciones prevalecen aquí cuentos decididamente realistas. El asunto estriba en el hecho de que en este libro aparece un tono nuevo, un motivo que se encontraba hasta entonces apenas esporádicamente en la obra cortazariana, diluyéndose en respectivos cuentos y tramas novelescas: el de la reflexión sobre la impenetrabilidad de los mundos humanos, sobre el entrecruzarse de esos mundos, sobre la faita de una verdadera comprensión entre dos personas que son o podríau ser entrañables entre sí. Y como antes - tengo en mente el clima de todo el libro y no de cuentos particulares-- los protagonistas de Certázar tratan sin resultado de traspasar el cristal de un sueño, romper el vidrio de un acuario que los había aislado del mundo real; así, ahora - en desvelo- luchan para trasponer la frontera que los separa de la otra persona. Pero también ahora sus esfuezos están condenados al infortunio. Lo único que logran alcanzar es organizar un juego de apariencias teatrales que les ayude a cuidar de la imagen de su pareja creada por ellos mismos y llegar así a la ilusión de armonía mutua, de un contacto verdadero con esa imagen que dura hasta que la realidad la borre. El hilo de comprensión, de identidad con otra persona puede aparecer por un momento, en el relámpago de un segundo, pero inmediatamente después cae de nuevo la cortina. Los esfuerzos humanos, como en los cuentos "fantásticos" de Cortázar, a dondequiera que se dirigen, quedan de antemano condenados al fracaso.

Luego de esta rápida referencia a la permanencia de las metamorfosis características del autor también en esta última colección de cuentos, para concluir quiero destacar un fenómeno interesante relativo a uno de los relatos incluidos, Otra vez. Es la historia de un joven que acudió por segunda vez a una indefinida oficina para completar las declaraciones hechas en una primera y desapareció misteriosamente. En la ya citada conversación con su traductora polaca el autor se refiere a este cuento como ejemplo de literatura comprometida ex post, ya que en el momento de escribirlo se trataba todavía de una "fantasía pura". Pero luego, cuando la gente en Argentina empezó a desaparecer no en una segunda vez, sino de primera, de las casas, de las oficinas, de la calle, "yo mismo - dice Cortázar - sentí un choque al entender que había presentido el futuro en todo su horror, que me había comprometido involuntariamente". Creo que tanto como Los premios, que no es una novela política pero ofrece una posibilidad de leerla "políticamente", este ex- 
celente cuento sirve de prueba contra aquellos que reclamaban a Cortázar un compromiso político en su literatura declarado expressis verbis.

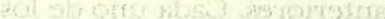

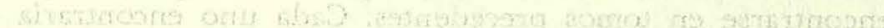

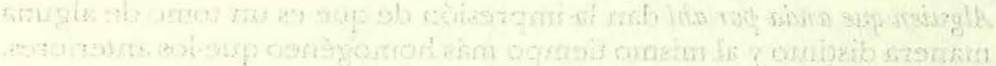
thack

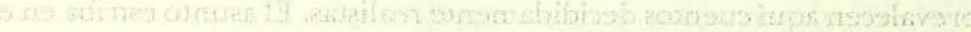

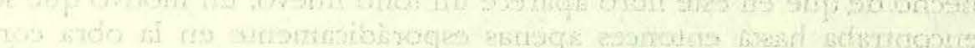

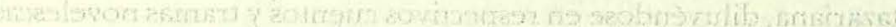

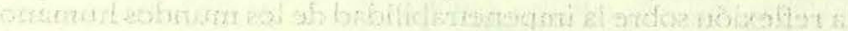

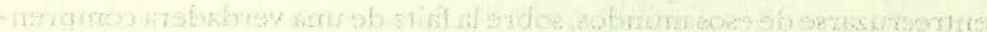

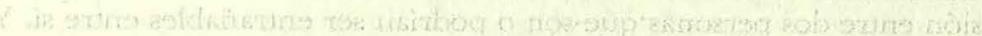

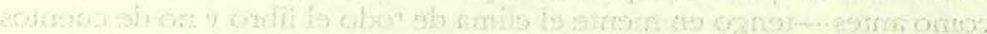

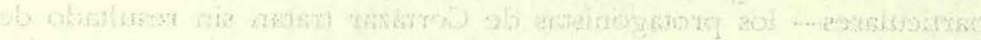

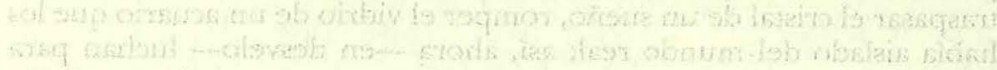

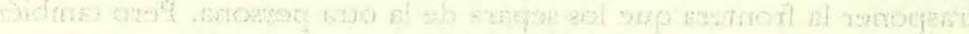

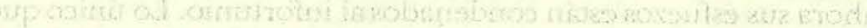

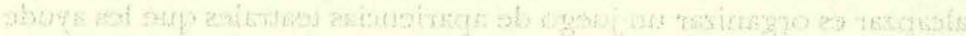

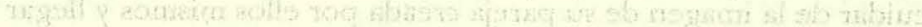

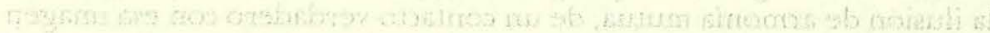

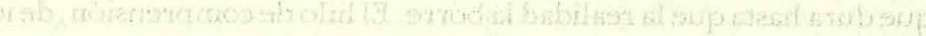

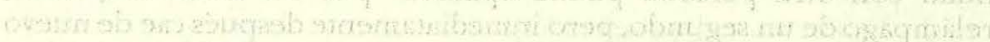

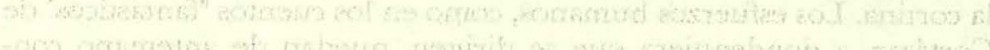

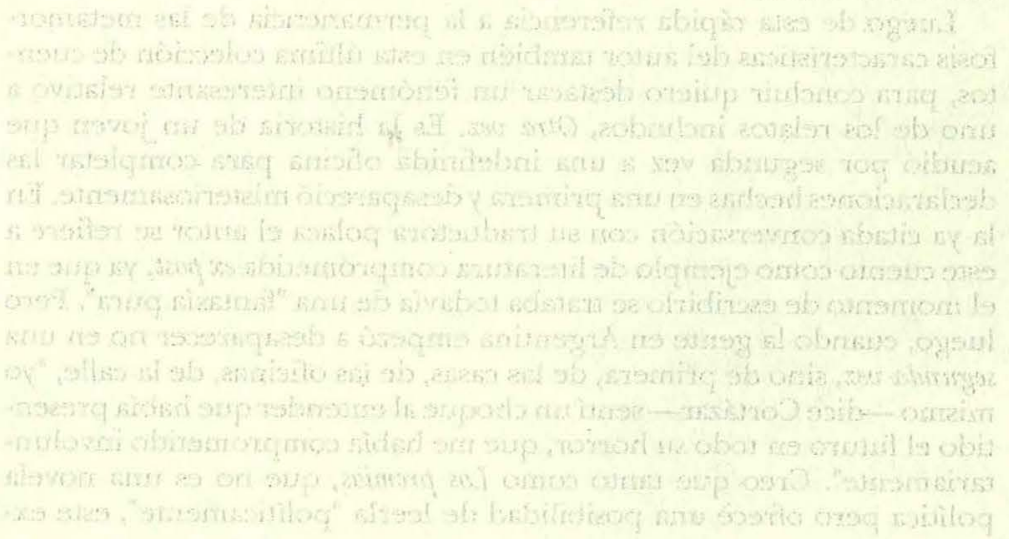

